See Article page 173

\section{Commentary: Intuitive is important: Opioid-sparing enhanced recovery after Thoracic surgery is not for everyone}

\author{
Andrew F. Feczko, MD, and \\ Alejandro C. Bribriesco, MD
}

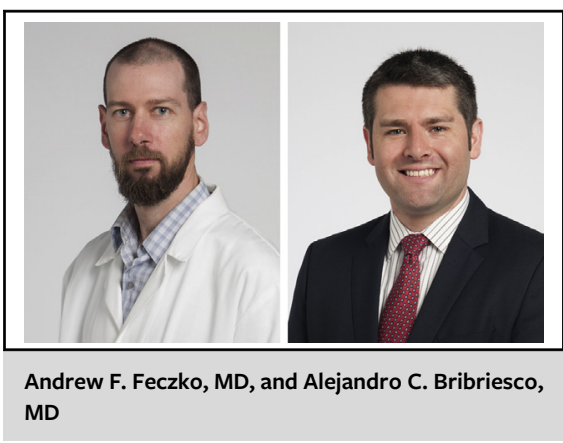

CENTRAL MESSAGE

Identifying risk factors for persistent postoperative opiate use is an important part of further improving a mature ERAS system for select patient populations after thoracic surgery.

liposomal bupivacaine described as an important aspect of the ERAS operative phase. Procedure-related and patient factors were assessed by multivariate analysis, with only patient factors reaching statistical significance. Specifically, preoperative opioid use (odds ratio, 28.8; 95\% confidence interval, 9.13-90.8; $P<.001$ ) and increase in age (odds ratio, $0.96,95 \%$ confidence interval, $0.93-0.99 ; P=.01)$ were the factors associated with differential postoperative opioid requirement.

It is tempting to dismiss these findings as intuitive. Preoperative opioids are recognized as a risk factor for postoperative opioid use ${ }^{4}$ and rarely does surgery acutely relieve preexisting pain to eliminate need for analgesia. The study is limited in postoperative data collection where patients themselves listed medications being used 6 to 8 weeks after surgery without granular detail on amount, quantity, or frequency of opioids used, nor on specific site of pain being treated. Hodges and colleagues ${ }^{3}$ describe a unique situation that is not necessarily widely replicable. Utilization of minimally invasive techniques is growing nationally, but does not currently approach the quoted $>90 \%$ rate. ${ }^{5}$ Also challenging generalizability is the availability of a robust and effective ERAS system - a goal requiring years of planning, buy-in, and adherence across specialties and providers. This primary finding may be novel within the authors' own ERAS system where previous studies did not identify preoperative opioids as a risk factor for postoperative use. 
But how should these observations impact our practice otherwise?

Intuitive findings are still relevant. This study is an example of a plan-do-study-act cycle of process improvement. ${ }^{6}$ By identifying specific factors leading to deviations in the established ERAS system, the team can now trial and implement additional pathways and techniques for highrisk patients such as narcotic-reliant, younger individuals. This is not necessarily a flashy result, but is an important example of the gradual, iterative process required for any institution to shape patient-oriented, precision care pathways while winnowing use of medications with potentially devastating secondary effects. We commend this group for demonstrating dedication to process improvement and continual, positive incremental change addressing the ongoing opioid public health crisis.

\section{References}

1. Kim MP, Chan EY, Meisenbach LM, Dumitru R, Brown JK, Masud FN. Enhanced recovery after thoracic surgery reduces discharge on highly dependent narcotics. J Thorac Dis. 2018;10:984-90.

2. Kim MP, Godoy C, Nguyen DT, Meisenbach LM, Chihara R, Chan EY, et al. Preemptive pain-management program is associated with reduction of opioid prescriptions after benign minimally invasive foregut surgery. J Thorac Cardiovasc Surg. 2020;159:734-44.e4.

3. Hodges JD, Nguyen DT, Doan J, Meisenbach LM, Chihara R, Chan EY, et al. Factors associated with home opioid use after thoracic surgery. J Thorac Cardiovasc Surg Open. 2021;5:173-86.

4. Kent ML, Hurley RW, Oderda GM, Gordon DB, Sun E, Mythen M, et al. American Society for Enhanced Recovery and Perioperative Quality Initiative-4 joint consensus statement on persistent postoperative opioid use: definition, incidence, risk factors, and health care system initiatives. Anesth Analg. 2019;129:543-52.

5. Seder CW, Magee MJ, Broderick SR, Brown LM, Blasberg JD, Kozower BD, et al. The Society of Thoracic Surgeons general thoracic surgery database 2019 update on outcomes and quality. Ann Thorac Surg. 2019;107:1302-6.

6. Taylor MJ, McNicholas C, Nicolay C, Darzi A, Bell D, Reed JE. Systematic review of the application of the plan-do-study-act method to improve quality in healthcare. BMJ Qual Saf. 2014;23:290-8. 